\title{
Setting and monitoring targets improves dairy farm performance
}

MARK MACINTOSH

Management Consultant, MAF Technology. Whakatane

\begin{abstract}
The process of setting targets and intensively monitoring performance on an Opotiki dairy farm improved milkfat production over one season by $6 \%$ when compared to surrounding farms. By comparing actual results with performance targets anumberofconstraintstoimprovcdmilkproduction were identified. The constraint given highestpriorty was the extended calving spread. Management was implemented to overcome this constraint with the result of a mean calving date 19 days earlier. This improvement was the major reason for the $6 \%$ production increase.
\end{abstract}

Keywords Comparative Farm Programme, targets, monitoring, constraints, pasture growth, utilised pasture

\section{Introduction}

In June of 1989 Bay Milk Products Ltd., adairycompany situated at Edgecumbe, engaged MAF to set up a Comparative Farm Programme. Four farms spread throughout the supply area were selected with the aim of providing useful on-farm information and advice which was to be extended to suppliers to improve factory throughput and payout.

This paper features one of the four Comparative Farms situated near Opotiki,newly owned by Gary and Linda Wenham. This farm was chosen as it represented a significant number of farms on hill country pumice soils and had potential for improved production.

\section{Features of property}

There were a number of important features of this particular property when the Wenhams took over. These included:

1. New owners with a new herd.

2. Effective grazing area of 66 hectares.

3. Effective area induded a lease block of 15 hectares which had a poor fertiliser history.
4. Hill country represented $60 \%$ of the effective grazing area.

5. Freedraining soils prone to drying out.

6. Long steep walk for the cows to the milkshed.

7. Unreliable water supply.

8. A history of brought in supplement in the form of grazing and silage estimated at between 3500 to 10000 bale equivalents per year.

9. A relatively high level of milkfat production of 374 $\mathrm{kg}$ milkfat/hectare compared with the zone average of $298 \mathrm{~kg}$ milkfat/hectare(1988/89 season).

\section{Method}

The Comparative Farm Programme involved a combination of intensive consultancy input, pasture datacollection, and extension of information to suppliers.

\section{Consultancy}

For each Comparative Farm in this programme a consultant was selected. This consultant had the responsibility to assist the owner(s) to achieve their goal of improved milkproduction. They were alsoresponsible for extension of information via reports and field-days. Consultancy visits were made regularly, within the last week of each month.

At the start of the programme the Wenhams and their consultant formulated a management plan for the following 3 years. This management plan included measurable performance targets andstrategies as to how these were to be acheived. Eachmonth actual information was collected and compared with these performance targets. Therelationshipbetween the two indicated what needed to be done. It was then a matter of analysing the options andmaking adecision. At theendofeachseason the management plan was reviewed with the rate and/or direction of the strategy altered as a result of improved knowledge gained from the monitoring and collecting of information.

For the purposes of this paper the management areas which have been analysed include: cow wastage; calving spread; herd quality; and pasture production. 
Pasture data collection

A standardised pasture measurement technique was used to measure the relative pattern of pasture growth (Radcliffe 1974). Pastures were under grazing except for small areas protected by cages over a 4-week period used for production measurements. Records of grass production throughout the season collected for 2 years (July 1989 to June 1990) were available.

Three sites were selected to represent the different dasses of soil type and topography. Each of the sites I describe as:

Site 1 : River flat

Site 2: Ridge flat

Site 3 : Sloping hill

For the purposes of this paper, when comparing pasture growth data, I have averaged sites 1 and 2 to representflatpastures with site 3onitsownrepresenting hill pasture

Average pasture growth for the whole farm was then calculated by weighting $40 \%$ for sites 1 and 2 and $60 \%$ for site 3, to take into account the relatively larger proportion of hill country. MAF Technology collected this data for the period July 1989 to June 1990 with Pasture Assessment Ltd carrying it on from July 1990

For the second season (1990/91) pasture either consumed by stock or taken as supplement was assessed. This was compared with the cage pasture production to assess the proportion of pasture growth that was utilised. This was assessed each month by measuring pre- and post-grazing pasture levels and daily grazing area. This information was then loaded into the following formula to determine the total pasture utilised.

Total pasture $=$ (prepost grazing level) $\mathrm{x}$ area grazed utilised
$(\mathrm{kg} \mathrm{DM})$

As the measurement was made only on one day per month the remaining days of the month were estimated based on the grazing plan adopted.

\section{Extension}

Extension of management and results was carried out via field-days (3-4 per year) and newsletters circulated monthly to all Bay Milk suppliers.

\section{Results}

Constraints

Alargenumber of constraintsrestrictingmilkproduction were identified over the last 2 years of the programme These included:

1. Cow wastage. This was higher than expected for both the 1989/90 and 1990/91 seasons as shown in Table 1.

Table 1 Cow numbers (milked 10 December) for the 1989/90 and 1990/91 seasons.

\begin{tabular}{lcc}
\hline Season & Target & Actual \\
\hline $1989 / 90$ & 168 & 162 \\
1990191 & 150 & 149 \\
\hline
\end{tabular}

Cow numbers in December were down compared with target by 6 and 9 for the $1989 / 90$ and 1990/91 seasons respectively. Assuming these cows would have produced equivalent to the herd average, this was a loss of around $1900 \mathrm{~kg}$ milkfat over the two seasons.

Themajorfactoridentifiedforthel ow erthanexpected cow numbers was empty cows showing up in the spring, especially first calvers. The strategy of improving heifer liveweights and feeding over the mating period were seen as the method to overcome this constraint. To achieve this, heifers were weighed regularly and fed according to their liveweight and compared with target over the period from weaning through to mating. Improved feeding during mating was achieved by restricting cow intakes in the early part of the season, thus building up feed ahead of the cows for mating.

2, Calving spread. This was longer than expected as shown in Table 2.

Table 2 Calving spread (weeks) and calving dates compared with target for the $1989 / 90$ and $1990 / 91$ seasons.

\begin{tabular}{lcccc}
\hline & \multicolumn{2}{c}{1989190} & \multicolumn{2}{c}{$1990 / 91$} \\
& Target & Actual & Target & Actual \\
\hline $50 \%$ calved & 2.2 & 3.7 & 2.2 & $2.2 ”$ \\
Last cow & 8.0 & 0.1 & 8.0 & 13.0 \\
Planned start & $4 / 8$ & $4 / 8$ & $25 / 7$ & $25 / 7$ \\
Mean date & $19 / 8$ & $29 / 8$ & $9 / 8$ & 1018 \\
\hline
\end{tabular}

- $18 \%$ herd induced

a $17 \%$ herd induced 


\subsection{Year I}

For the first season $(1989 / 90)$ the calving rate was slower than expected with $50 \%$ of the herd taking 3.7 weeks to calve compared with the target of 2.2 weeks. The total calving period was on target due to $18 \%$ of the late calvers induced. The mean calving date was 10 days behind target. Based on a production per cow of $0.7 \mathrm{~kg}$ milkfat per day over this period, for 150 cows, the loss in production was estimated at around $1000 \mathrm{~kg}$ milkfat.

Afterthisresultthedecisionwas tobring theplanned start of calving forward 10 days to 25 July, cull heavily for late calvers, vet slow cycling cows, and induce within the first 3 weeks of calving

\subsection{Year 2}

For the second season (1990/91) the calving rate was much improved as expected due to the earlier start of calving and early induction of $17 \%$ herd within the week 2 of calving. As a result the 3-week target was achieved.For the remainder of the calving, the rate was slow with up to 5 cows taking over 13 weeks to calve from the planned start. The mean calving date was 19 days ahead of the previous season. This equated to an improvement of around $2000 \mathrm{~kg}$ milkfat over and above the previous season, based on the same cow numbers and per cow production as above.

\section{High proportion of low producers}

This was analysed in the second season by selecting those cows, based on last herd test, with a New Performance Index $(\mathrm{PI})$ at or below the average herd New PI minus 10 points. This was not a standard technique, but it was effective when compared with other herds analysed at the same time on the same basis. The result of this analysis is shown in Table 3.

Table 3 Percentage of cows at or below the average herd PI minus 10 points, for the $1990 / 91$ season (based on last herd test).

\begin{tabular}{lc}
\hline Herd & \% Herd \\
\hline Wenham & 36 \\
District average & 17 \\
District best & 2 \\
\hline
\end{tabular}

The results showed Wenhams' herd to have a large number of low producing cows when compared with other herds. No major decision was made to cull the known low producers. However the best options put forward were to buy in cows to replace low producers or reduce cow numbers for one season and rebuild in future, seasons.

\section{Pasture production}

Results of cage pasture growth measurements in the first year showed the farm produced much the same as the expected target, as shown in Table 4.

Table 4 Annual pasture growth of the flat and hill for the period July to June for the $1989 / 90$ and 1990191 seasons. Cage growth ( $k$ g DM/ ha)

\begin{tabular}{lccrc}
\hline Land type & \multicolumn{2}{c}{$1989 / 90$} & \multicolumn{2}{c}{$1990 / 91$} \\
& Actual & Target & Actual & Target \\
\hline Flat & 14155 & & 15578 & \\
Hill & 10655 & & 11365 & \\
Farm average' & 12055 & 12000 & 13050 & 12500 \\
Utilised pasture & $\mathrm{n} / \mathrm{m}$ & & 6560 & \\
\hline
\end{tabular}

Weighted $60 \%$ hill: $40 \%$ flat

This result was surprising as the pasture supply was lower than ideal for most of the season. The condusion was that either the target was set too low; or the farm did not grow as much as the cages indicated. To develop this furthur the feed utilised by stock or taken as supplement was measured in the second season. This was then related to the cage pasture production. The result is shown in Table 4.

The amount of pasture utilised during the season was $66 \%$ of that grown in the cages. This indicated that $34 \%$ of pasture grown was being lost from the farm system. It was conduded that cagegrowthoverestimated whole farm pasture production.

Hill pastures were shown to produce $25 \%$ and $27 \%$ less pasture than flat pastures for the $1989 / 90$ and $1990 /$ 91 seasons, respectively, as shown in Table 4. This highlighted the importance of knowing the balance of hill toflatonthefarm. Lackofmoistureandlow fertility appeared to be the major constraints limiting pasture production on the hills.

When monthly rainfall was compared with pasture production there was a strong relationship during the summer/autumn period as shown in Figure 1. This was not the case during the winter/spring period when soil temperature appeared to have the major influence. This constraint was seen as difficult to overcome because of the climate having such a large impact.

Suggested improvements were to prevent over grazing of hill pastures in summer and apply fertiliser consistently at above maintenance rates. 


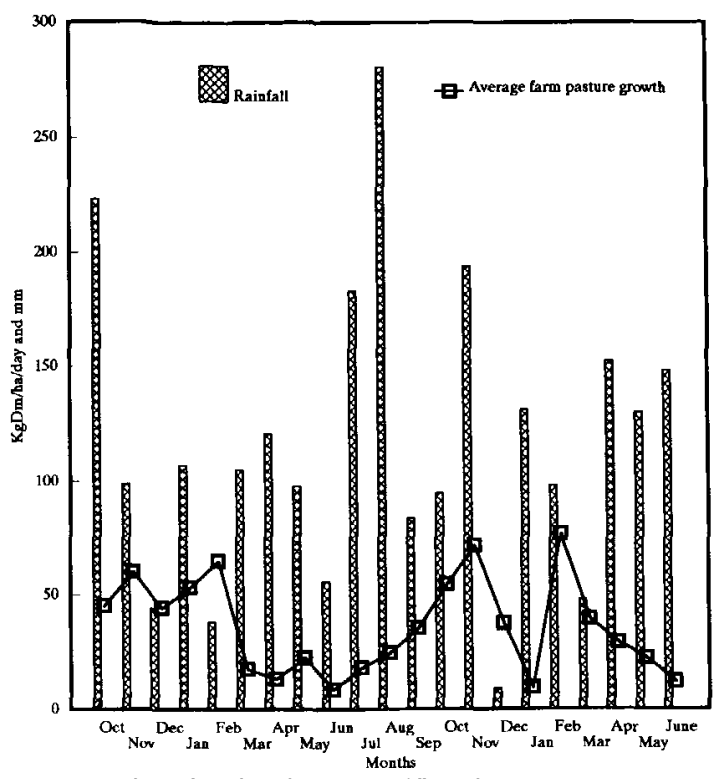

Figure 1 The relationship between rainfall and average farm pasture growth (cage) for $1989 / 90$ and $1990 / 91$ seasons.

\section{Milkfat production}

The results of the $1989 / 90$ and $1990 / 91$ seasons are shown in Table 5.

Table 5 Actual milkfat production (kg) for $1989 / 90$ and $1990 / 91$ seasons.

\begin{tabular}{lrr}
\hline Factor & $1989 / 90$ & $1990 / 91$ \\
Total milkfat $(\mathrm{kg})$ & 19600 & 19400 \\
Milkfat/cow (kg/cow) & 120 & 129 \\
Milkfat/hectare (kg) & 297 & 294 \\
Cows milked (1 Dec.) & 164 & 150 \\
District milkfat $(\mathrm{kg})$ & 21972 & 20404 \\
\hline
\end{tabular}

- Average of 31 farms on surrounding country

Milkfat production in the first year (1989/90) was more or less set when the Wenhams arrived on the property. The first year was seen as a benchmark on which to gauge future production targets. When the second season was compared with the first there was a slight drop of around 1\%. Surrounding farms on similar country over the same period dropped on average $7 \%$. This meant an overall improvement of $6 \%$ for the Wenhams which equated to $1180 \mathrm{~kg}$ milkfat. This was a positive result and was attributed almost entirely to a 19 day earlier mean calving date.

\section{Conclusion}

The Comparative Farm, owned by Gary and Linda Wenham, produced a positive production response for the 1990/91 season. There lies the opportunity for other farms to achieve a similar result by learning from this exercise. To produce successful results the following management process should be adopted.

1. Clearly identify your goals i.e.what you wish to achieve.

2. Set performance targets, in relation to these goals, forallmeasureablefactors ie milk production, calving spread, stock liveweights, pasture production, cow condition.

3. Collect actual data on these factors.

4. Analyse the difference between actual and target performance. From this comparison decide whether action needs to be taken.

5. If action is to be taken, formulate a strategy to achieve the target by assessing all available opportunities and choosing the option which best meets your needs.

6. Use expert advice when implementing the chosen option especially where experience is limited.

7. Monitor the result to determine if targets have been achieved and to assess the financial benefit of the management put in place.

8. Review targets.

When setting targets at the start of such aprogramme the following needs to be taken into account:

1. Target growth rates to be used for feed budgets need to be lower than those collected by cages.Suggested growth rates to be used for feed budgets on dry hill and flat country are:

\begin{tabular}{lcccccccccccc}
\hline & \multicolumn{1}{c}{ Jul Aug Sep Oct Nov } & Dec Jan Feb Mar Apr May Jun \\
\hline Flats & 12 & 25 & 35 & 50 & 60 & 40 & 40 & 50 & 35 & 20 & 20 & 15 \\
Hill & 10 & 15 & 25 & 35 & 45 & 30 & 25 & 35 & 20 & 15 & 12 & 7 \\
\hline
\end{tabular}

2. The proportion of hill to flat pasture is vital information to provide average farm pasture growth for feed budgeting. This is best determined from an aerial photo and using the above growth rates.

3. The past history of the property and management needs to be assessed carefully, mainly with respect to fertiliser applications and off farm feed inputs such as grazing and brought in supplement.

\section{ACKNOWLEDGEMENTS}

The author would like to thank Gary and Linda Wenham who made their farm available for the Comparative Farm Programme and allowed the data to beusedforthis paper; Barry Keene from Bay Milk Products Ltd and Graeme Piggot from Pasture A ssessment Ltd for the availability of pasture growth data; Chris Glassey from Livestock Improvement and all those who provided constructivecommment in theconstruction of this paper. 